\title{
CLINICAL OUTCOMES OF LOCKING COMPRESSION PLATE FIXATION THROUGH MINIMALLY INVASIVE PERCUTANEOUS PLATE OSTEOSYNTHESIS IN THE TREATMENT OF DISTAL TIBIAL FRACTURE
}

\author{
D. Venkateswara Rao' ${ }^{1}$ K. Venkatasesha Reddy², Anvesh Sangepu ${ }^{3}$
}

\section{HOW TO CITE THIS ARTICLE:}

D. Venkateswara Rao, K. Venkatasesha Reddy, Anvesh Sangepu. "Clinical Outcomes of Locking Compression Plate Fixation through Minimally Invasive Percutaneous Plate Osteosynthesis in the Treatment of Distal Tibial Fracture". Journal of Evolution of Medical and Dental Sciences 2015; Vol. 4, Issue 60, July 27;

Page: 10516-10525, DOI: 10.14260/jemds/2015/1515

ABSTRACT: BACKGROUND: Distal diametaphyseal tibia fracture though requires operative treatment is difficult to manage. Conventional osteosynthesis is not suitable because distal tibia is subcutaneous bone with poor vascularity. Closed reduction and minimally invasive percutaneous plate osteosynthesis with locking compression plate (LCP) has emerged as an alternative treatment option because it respects biology of distal tibia and fracture hematoma and also provides biomechanically stable construct. OBJECTIVES: To find out suitability of minimally invasive percutaneous plate osteosynthesis with Locking compression plate for distal diametaphyseal tibia fracture including union time and complications. METHODS: Twenty patients with closed distal tibia fracture with or without intra articular extension (AO classification type- A1, type-A2, type-A3) treated with minimally invasive percutaneous plate osteosynthesis with Locking compression plate were prospectively followed for average duration of 12 months. RESULTS: Average duration of injury-surgery interval was 4.5 days (Range 3-7 days) all fractures got united with an average duration of 23.5 weeks (range17-30weeks). No non-union or mal-union were found. There was one superficial infection found which healed with extended period of intravenous antibiotics.

KEYWORDS: Distal tibia, LCP, Osteosynthesis plate.

INTRODUCTION: Fractures of the distal tibia can be challenging to treat because of limited soft tissue, the subcutaneous location and poor vascularity. ${ }^{1}$ Fractures of distal tibia remain a controversial subject despite advances in both non-operative and operative care. The goal in expert care is to realign the fracture, realign limb length and early functional recovery. ${ }^{2}$

Fractures of distal tibia remain one of the most challenging for treatment because of high complication rates both from initial injury and also from treatment. 3,4 All these fractures are severe injuries. They are increased in frequency because of higher incidences of Road Traffic Accidents.

Accounts to $1 \%$ of all lower extremity fractures, $10 \%$ of tibial fractures and bilateral in $0-8 \%$ and compartment syndrome in $0-5 \%$.

Most of these fractures are managed with an operative intervention such as closed reduction and intramedullary interlocking (IMIL) nailing or open reduction and internal fixation (ORIF) with plating or closed reduction and per cutaneous plating or external fixators. Each of these techniques has their own merits and demerits.

Conservative treatment can be applied to stable extra-articular fractures with minimal shortening; however, malunion, shortening, restricted movements and osteoarthritis have been reported in these fractures.5,6,7 


\section{ORIGINAL ARTICLE}

These distal tibial metaphyseal fractures are generally not suitable for intramedullary nailing. They have reported with higher rate of malunion because it is difficult to achieve two distally locking screws. Failures in controlling distal fragments may lead to deformities and mal union. ${ }^{8}$

External fixation can be useful in open fractures with soft tissue injury which preclude nail or plate fixation, but may result in inaccurate reduction, a relatively high rate of malunion, or non-union and pin tract infection ${ }^{7}$. Hence not preferred as definitive fixation method. ${ }^{9}$

Classic open reduction and internal plate fixation require extensive soft tissue dissection and periosteal stripping even in expert hands, with high rates of complications, including infection and delayed union and non-union. ${ }^{10}$

In the last decade, minimally invasive percutaneous osteosynthesis (MIPPO), performed by indirect reduction, has become a successful treatment modality in complex fractures of the lower extremity.11,12 The aim of MIPPO is to preserve the osteogenic hematoma of the fracture and periosteal blood supply while preventing iatrogenic soft tissue damage. Vascular injection studies have found that cases treated by MIPPO found to result in higher preservation of periosteal circulation. ${ }^{13,14}$

Therefore, minimally invasive osteosynthesis offers the best possible option as it permits adequate fixation with reduced soft tissue dissection and exposure resulting in low surgical trauma and thus preservation of the blood supply in a biological manner with lesser evacuation of osteogenic fracture hematoma. The locking compression plate (LCP) provides enhanced stability in these situations with a minimum number of screws.12 Locked screws prevent the plate from pressing the bone, preserving periosteal blood supply. This system stimulates callus formation due to flexible elastic fixation. The anatomic shape of the plate prevents malalignment of the fracture and provides a better axial and angular weight distribution. ${ }^{15}$

\section{AIMS AND OBJECTIVES:}

1. To evaluate the results of Minimally Invasive Percutaneous Plate Osteosynthesis (MIPPO) in treatment of distal tibial fractures

2. To study the surgical difficulties encountered during the procedure.

3. To study the efficacy of minimally invasive percutaneous plate osteosynthesis in treating distal tibial fractures in terms of:

- Time required for the union of fracture.

- Range of motion of ankle joint.

- Rate of malunion and non-union.

- Rate of infection.

- Failure of the implant.

\section{REVIEW OF LITERATURE:}

- Treatment of distal tibia fractures remains controversial, and the optimal method of treating these devastating injuries remains unknown. Poor results have been the rule, leading some to refer to this fracture as inoperable with recommendations for closed management. ${ }^{16}$

- Historically fractures of the lower end of the tibia into the ankle joint were regarded as 'not being amenable to internal fixation'. Skeletal traction through the calcaneum was the standard treatment and post-traumatic osteoarthritis and stiffness is the rule. ${ }^{17}$ 
- In 1968 Reudi published a paper on this topic, describing the fracture, principles of treatment and a classification system. His experience with immediate fixation of tibial fractures demonstrated durable results and few complications. 18,19

- Ovadia and Beal's concluded that the final functional result correlates well with the accuracy of articular reduction.

- Elter and Ganz reported ninety five percent good results with open reduction. Blauth et al studied the functional outcome of tibial pilon fractures treated by three different modalities. Primary internal fixation with a plate following the AO-ASIF principles $(n=15)$, one-stage minimally invasive osteosynthesis for reconstruction of the articular surface with long-term transarticular external fixation of the ankle for at least four weeks $(n=28)$; and a two-stage procedure entailing primary reduction and reconstruction of the articular surface with minimally invasive osteosynthesis and short term transarticular external fixation of the ankle joint followed by secondary medial stabilization with a plate using the MIPO technique. $(\mathrm{n}=8)$. They found that none of the patients who required secondary arthrodesis (23 percent of all cases) were in the group who had undergone two-step surgery ( $p<0.05)$. The range of ankle movement was much greater in the two-step group than in the others; these patients also had less pain, more frequently continued working in their previous profession, and had fewer limitations in their leisure activities. They concluded that the two stage management protocol is satisfactory in achieving union with less complications and good functional outcome. 20

- Borrelli et al studied the effects of various methods of plating in tibia in human cadavers. They found that Open plating of the medial aspect of the distal tibia caused a statistically significant greater disruption of the extra osseous blood supply of the metaphyseal region than did percutaneously applied plates. They concluded that disruption of these extra osseous vessels following.

- Fracture and subsequent operative stabilization may slow healing and increase the risk of delayed union and non-union.

- These findings support current efforts to develop less invasive methods and implants for operative stabilization of distal tibia fractures. ${ }^{21}$

- Rhinelander F in his study of vascular supply to tibia and its response to fracture made the following observations; the vascular supply of the tibia is supplied by intramedullary vessels, which provide nourishment to all of the intramedullary contents and to $2 / 3^{\text {rd }}$ of the cortical bone. The outer $1 / 3$ of the cortex receives its blood supply from the overlying soft tissues. In patients with displaced long bone fractures, the intramedullary vascularity frequently is disrupted and the traumatized bone and soft tissues must rely solely on the remaining periosteum and other soft tissues for nutrition.

- Therefore, any extensive surgical dissections of the bone fragments may devitalize the remaining vascular pedicles, resulting in delayed union or non-union of the fracture. ${ }^{22}$

- Zelle et al in their review of 1125 patients with distal tibia fractures, treated by different methods found that, non-operative treatment $(n=521)$ was associated with a non-union rate of $1.3 \%$, a malunion rate of $15 \%$, and $4.3 \%$ required secondary surgical procedures. Primary intramedullary nailing $(\mathrm{n}=489)$ was associated with a non-union rate of $5.5 \%$, an infection rate of $4.3 \%$, a malunion rate of $16.2 \%$, and $16.4 \%$ of the patients required secondary surgical 


\section{ORIGINAL ARTICLE}

procedures. Plate fixation $(\mathrm{n}=115)$ was associated with a non-union rate of $5.2 \%$, an infection rate of $2.6 \%$, a malunion rate of $13.1 \%$ and $8.7 \%$ required secondary surgical procedures.

PATIENTS AND METHODS: The present study was undertaken at the department Orthopaedics, Government General Hospital, Vijayawada. This study involved both male and female patients with distal tibia fractures, who presented to Government General Hospital, Siddhartha Medical College, Vijayawada.

20 patients who had distal tibia fractures and met the selection criteria were treated with minimally invasive percutaneous plating during the period from July 2012 to July 2014 were included in the study.

Fig. 1: Distal Tibial Locking Compression Plates.

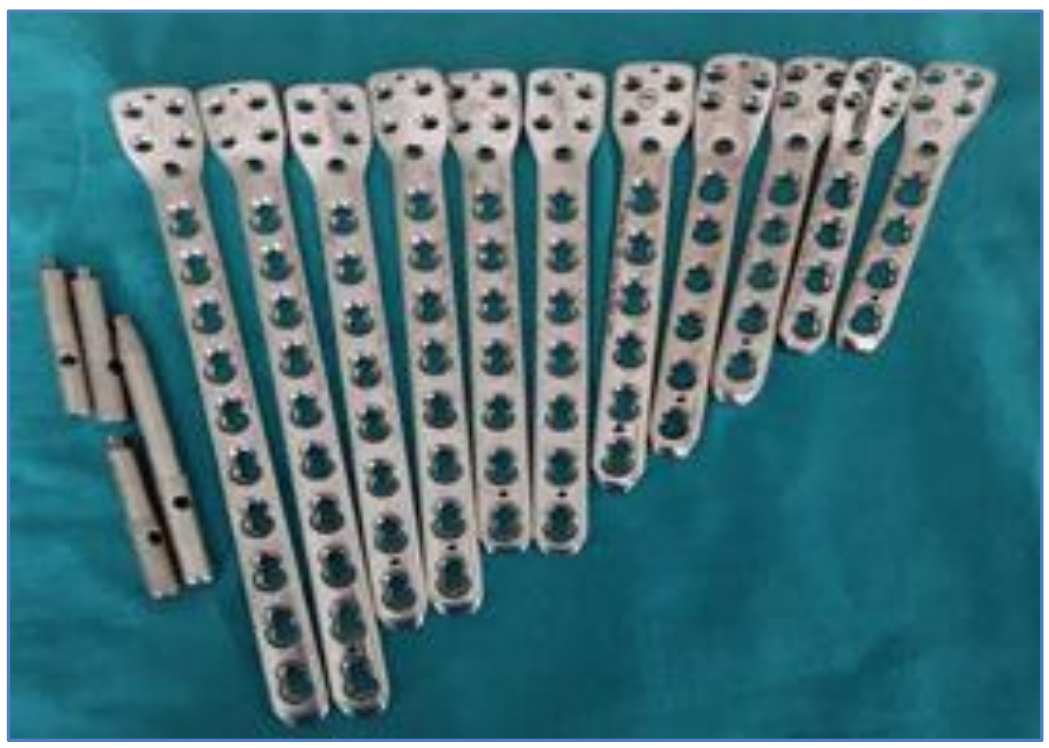

Fig. 1

All the cases were fresh fractures and were traumatic in nature. On admission general condition of the patient was assessed with regards to hypovolemia, associated orthopaedic or other systemic injuries and resuscitative measures were taken accordingly. A thorough clinical examination was performed including detailed history relating to age, sex, occupation, mode of injury, past and associated medical illness.

Routine investigations were done for all the patients. All patients were evaluated clinically and radiologically to assess for any other injuries. Radiographs were taken in two planes, AP and Lateral views. Patients were operated as early as possible, once the general condition of the patients was stable and patients were fit for surgery.

\section{Inclusion Criteria:}

- $\quad$ Age $>20$ years (skeletally mature patients).

- $\quad$ Fractures distal third tibia.

- $\quad$ Closed displaced unstable fractures. 


\section{ORIGINAL ARTICLE}

\section{Exclusion criteria:}

- Open fractures of distal third tibia.

- Neurovascular injury.

- Fractures proximal third and mid third tibia.

- Pathological fractures.

- Skeletally immature patients.

- Patients in whom time log between injury and surgical intervention exceeds 3 weeks.

OBSERVATIONS AND RESULTS: The present study includes 20 distal third tibial fractures treated with minimally invasive percutaneous plate osteosynthesis from July 2012-July 2014 in the Department of Orthopaedics, Siddharatha Medical College, Government General Hospital, Vijayawada. The patients were followed up for an average of 12 months. All the patients were available for follow up.

Twenty patients who had distal tibial fractures were included in our study group. The duration of follow-up ranged from 8 to16 months (Average 12months). There was 14 men and 6women, ranging in age from 23 to 67 years old, with an average age of 41.9years. In our study there were10 right sided and 10 left sided distal third tibia fractures. Most of the patients in our study group are below 40years, and most common mode of injury is Road Traffic Accidents. Majority of the patients are male (70\%) and only 30\% were females. The major cause of fracture in our study was Road Traffic Accidents (80\%). Right tibial fracture constituted majority of the patients. 10 patients $(50 \%)$ were having right tibial fractures. All the fractures in our study were closed. Majority were of A1 type (40\%) followed by A2 type (30\%).

Most of our cases were uneventful and the only complication of superficial wound infection was noted in 1 case (5\%) which subsided on treatment with regular dressing and intravenous antibiotics. it is clear that MIPO results in less surgical trauma to the soft tissues and less operative time. The time of partial weight bearing was decided on the type of fracture, adequacy of fixation and the radiological picture at the time of follow up. Most patients started partial weight bearing around 7-8 weeks post-surgical fixation. The time of full weight bearing was usually between 7-14 weeks with an average time of full weight bearing of 10.2 weeks in our study group.

Union was defined as the presence of bridging callus on two radiographic views and the ability of the patient to bear full weight on the injured extremity. All the fractures united. The time to union was between 17 to 30 weeks with an average of 23.75 weeks in our study group. A malunion was defined as angulation in coronal plane (Varus-valgus) of more than 5 degrees, in the saggital plane (Anterior-posterior) angulation of $>10$ degrees, or more than $10 \mathrm{~mm}$ of shortening. None of the patient with distal tibia fracture had a valgus/varus alignment of more than 5 degrees.

None of the patients had more than 10degree of angulation in saggital plane and none had a shortening of more than $10 \mathrm{~mm}$. Detailed analysis of function of the patients with distal tibia fractures was done on the basis of following Ankle evaluation scoring system -AOFAS [American Orthopaedic Foot and Ankle Society Ankle-Hind foot Scale]. In our study of patients with fractures of distal tibia treated with MIPO, 10\% patient had Fair result, 10\% patient had good results, $80 \%$ patients had excellent results. 


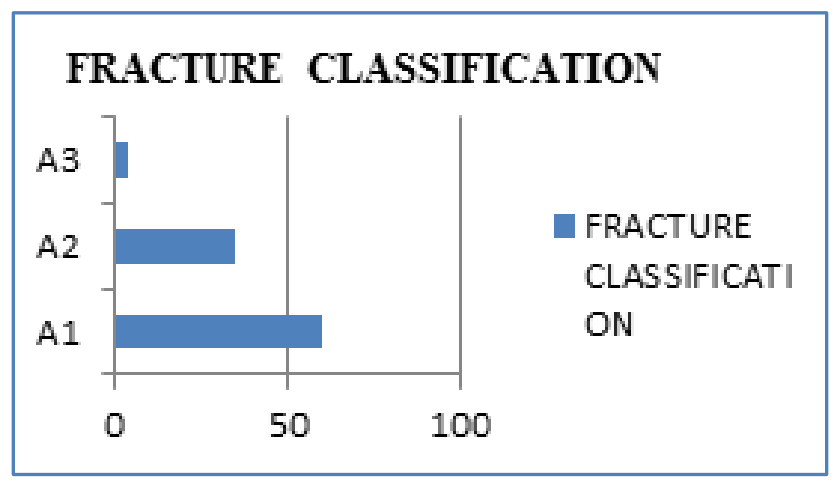

DISCUSSION: Distal tibial fractures remain one of the most substantial therapeutic challenges that confront the orthopaedic traumatologist. Though conservative management of these fractures has been described 5,8 these methods have been largely superseded by operative techniques for displaced or irreducible fractures, and fractures with intra-articular extension.

MIPO is by now an established technique of management of fractures of the distal third tibia. Minimally invasive plating techniques reduce the iatrogenic soft tissue injury and damage to bone vascularity, and also preserve the osteogenic fracture hematoma. Minimally invasive techniques are based on principles of limited exposure, indirect reduction methods and limited contact between bone and implant. As a result of these principles this technique, as seen in present study, avoided major soft tissue complications and shortened the length of the patient's stay in the hospital. Biological fixation of tibial distal third fractures is beneficial and technically feasible. The advantages are: it reduces injuries on soft parts, it does not compromise bone vascularisation and presents a low complication rate, especially when compared to open reduction and internal fixation.

Fig. 2: Pre-Operative x ray.

Fig. 3: Post-Operative

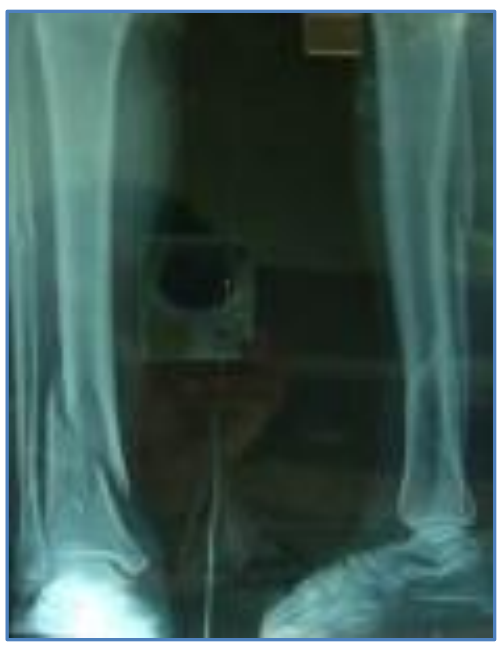

Fig. 2

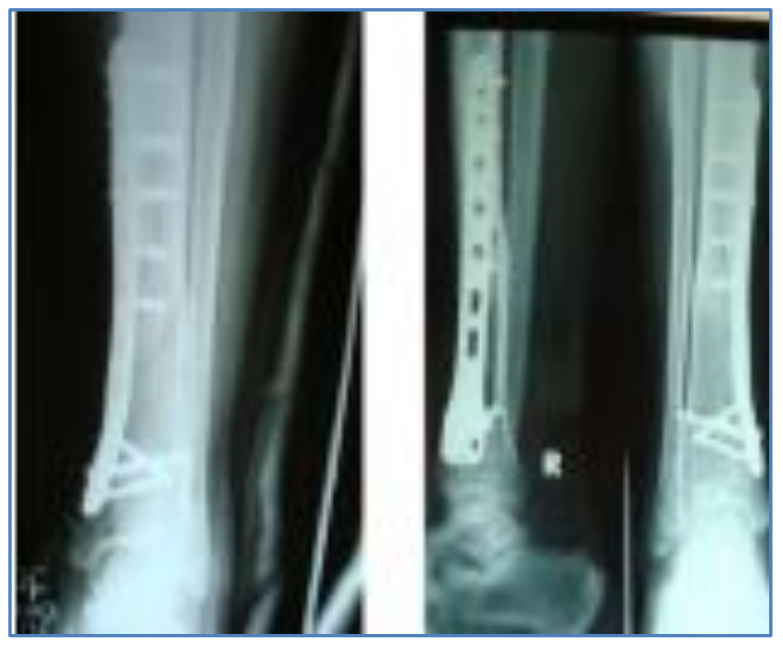

Fig. 3 
The present study was undertaken to evaluate the results of Minimally Invasive Percutaneous Plate osteosynthesis (MIPPO) in treatment of distal third tibial fractures

Twenty patients with closed distal third tibial fracture with or without intra articular extension (AO classification: 12type 43A1, 7 type 43A2, 1type 43A3, treated with MIPPO with LCP were prospectively followed for average duration of 12 months (Range 8-12 months).

We evaluated our results and compared them with those obtained by various other studies utilizing different modalities of treatment, our analysis is as follows:

Age distribution: Our study revealed the average age of patients with such injuries to be 42years (23-67). It is comparable with a study on similar fractures conducted by various authors.

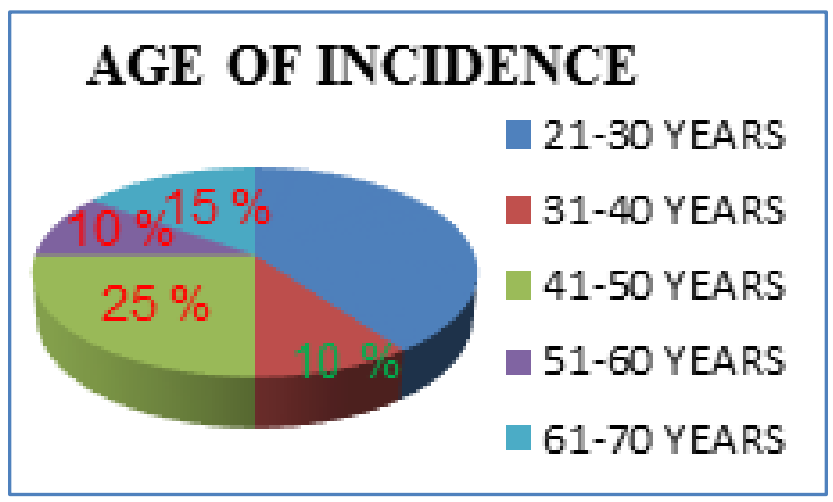

Sex Distribution: The sex distribution in our study in the treatment of distal third tibial fractures with MIPPO showed that there were 14 men and 6 women.

Nature of Violence: Majority of the cases sustained fractures from road traffic accidents i.e. 16 cases (80\%). 4 patients had sustained fracture after a fall. R.T.A was most common mode of injury in present series.

RESULTS: The age of the patients ranged from 23 to 65years with mean age of 42years. Most of the patients were in the age group of 20-40years. There were 10 male and 10 female patients included in the study. The mode of injury in the majority of the patients was road traffic accidents. The majority of the fractures operated in our study were extra-articular fractures, i.e. A0/OTA 43-A (100\%).5 patients $(25 \%)$ had a both bone leg fracture, with majority of the fibular fractures occurring at the level of the tibial fracture, suggesting a bending mechanism. Out of the 5 patients with an associated fibular fracture, only 1 patients needed fixation of the fibula (5\%), and is fixed with one third tubular plate. The average duration between trauma and surgery was 4.5 days with a range of 3-7days.

Most of the cases were operated upon within 4days of injury (86\%). The average operative time was $60 \mathrm{~min}$ with a range of 70-120min. The majority of the fractures were operated within 100 min of operative time $(90.0 \%)$. Operative time was longer in fractures in which needed fixation of the fibula. The average fluoroscopy time was $50 \mathrm{sec}$ with a range of $34 \mathrm{sec}-60 \mathrm{sec}$. Post operatively the limb was elevated and a removable below knee slab was given. Toe touch weight bearing and knee range of motion was started on the $2^{\text {nd }}$ postoperative day. Sutures were removed at $11^{\text {th }}$ postoperative day, slab was continued for 4 to 6 weeks. 


\section{ORIGINAL ARTICLE}

Weight bearing was increased depending on the progress of clinical and radiological fracture healing. Full weight bearing was allowed at fracture union, which was defined as union in 3 cortices and painless weight bearing.
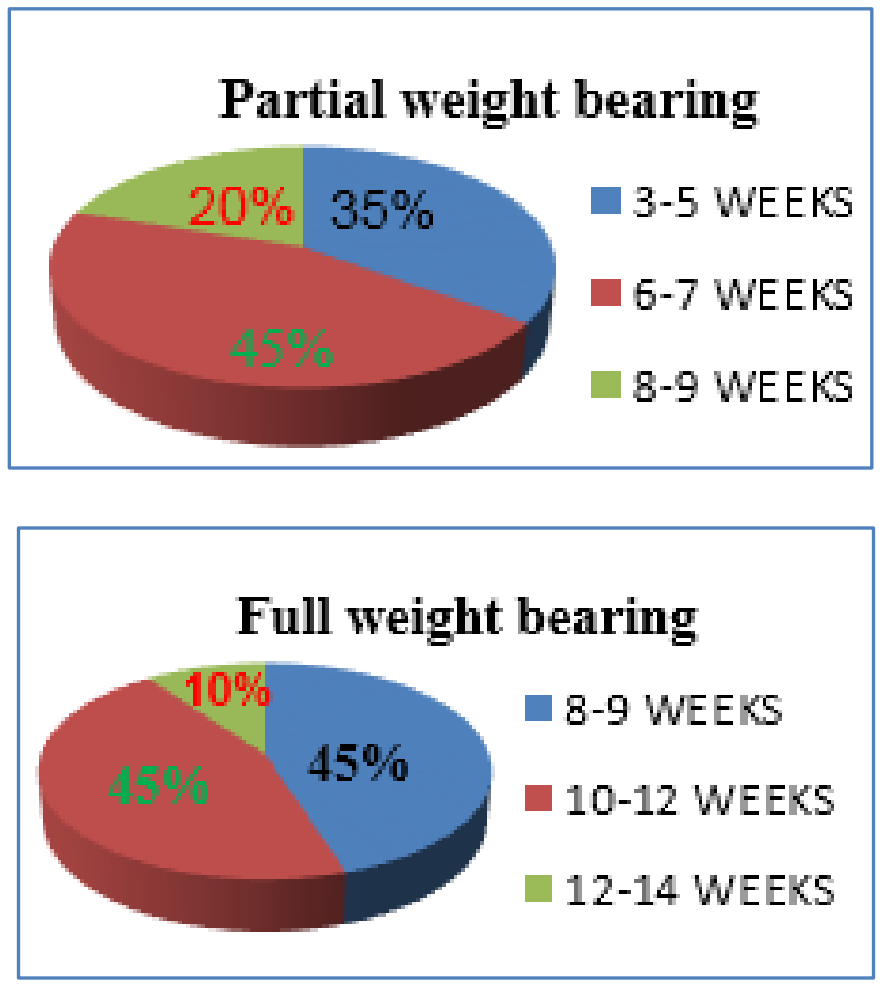

The mean time for radiological union was 23.75 weeks with a range of 34 to 60 weeks. On union, all of the 12 patients had an AOFAS score of 90 or greater out of a possible 100 points. The mean score was 90.25. We encountered superficial infection in one of our patient which was managed with dressings and appropriate antibiotics. As the study progressed we realised that the key to preventing infection was gentle handling of the soft tissues. On long term follow up of the patient's the superficial infection healed well. The infection rate using MIPO (5\%) is favourable compared with ORIF with plates (15-35\% deep infection rates) and also with external fixation $(20-50 \%$ pin track infection).

A malunion was defined as angulation in a coronal plane (Varus -valgus) $>5$ degrees, saggital plane (Anterior -posterior) angulation of $>10$ degrees or $>10 \mathrm{~mm}$ of shortening. In our series, none of the patients had more than 10 degree of angulation in saggital plane and none had a shortening of more than $10 \mathrm{~mm}$. These results are comparable with the results of similar studies where in the malunion rate is reported to be $2-5 \%$.

In our series no patient had implant failure. This is also comparable to other similar studies, Bonker et al which have reported a 0-10\% incidence of plate exposure, most commonly at the distal insertion site. In most of the other studies the implant distal tibial locking plate removal is mainly due to symptomatic skin impingement over the medial malleolus.

In our series, no patient developed fat embolism, compartment syndrome, peroneal nerve palsy or reflex sympathetic dystrophy. 


\section{ORIGINAL ARTICLE}

All patients were happy with the cosmetic results because very little residual swelling was noted and the surgical wounds were rather small and healed without much scarring.

\section{CONCLUSION \& SUMMARY:}

- A short series of result of our study were analyzed and the overall results have encouraged us in preferring the MIPPO over conventional ORIF.

- Real advantages lie in the prevention of soft tissue problems and the possibilities for earlier and even single-stage operative procedures, contributing to a favourable outcome.

- The MIPPO technique is a reliable fixation approach to fractures of the distal third tibia, preserving most of the osseous vascularity and fracture haematoma and thus providing for a more biological repair.

- This technique can be used in fractures where locked nailing cannot be done like distal tibial fractures with small distal metaphyseal fragments, vertical split and markedly communited fractures.

- Due to preserved vascularity, there is lesser incidence of delayed union and non-union.

- There was reduced incidence of infection due to limited exposure. Infection can also be prevented by careful handling of soft tissues and by minimising the operating time.

- Simpler follow-up, escaping repeated visits, plaster changes, wedging and check radiographs.

- Minimal hospital stay and early returns to activities.

- Cost effective as per reduced need for outpatient care, earlier return to work and lessened of sick benefit Compensation.

\section{REFERENCES:}

1. Howard JJ, Barie et al. A prospective study of evaluating incision placement and wound healing for tibial plafond fratures. J Orthop trauma. 2008; 5: 250-255.

2. Mu"ller ME, Allgo"wer M, Schneider R, et al. Manual of Internal Fixation. Techniques recommended by the AO-ASIF group. Berlin, Springer-verlag, 1991

3. Reudi T, Matter P, Allgower $\mathrm{M}$ et al. Intra-articular fractures of the distal tibial end. Helv Chir Acta. 1968; 35: 556-582.

4. Reudi TP, Allgower M et al. The operative treatment of intra-articular fractures of the lower end of the tibia. Clin Orthop Relat Ras 1979(138): 105-110.

5. Kai H, Yokoyama K, Shindo M, Itoman M. Problems of various fixation methods for open tibia fractures: experience in a Japanese level I trauma center. Am J Orthop 1998; 27: 631-6.

6. Othman M, Strzelczyk P. Results of conservative treatment of "pilon" fractures. Ortop Traumatol Rehabil 2003; 5: 787-94.

7. Ovadia DN, Beals RK. Fractures of the tibial plafond. J Bone Joint Surg Am1986. 68(4): 543-551.

8. Kneifel T, Buckley R. A comparison of one versus two distal locking screws in tibial fractures treated with unreamed tibial nails: a prospective randomized clinical trial. Injury 1996, 27: 271-273.

9. Watson JT, Moed BR, Karges DE, Cramer KE. Pilon fractures. Treatment protocol based on severity of soft tissue injury. Clin Orthop Relat Res 2000, 375: 78-90

10. Martin J, Marsh Jl, Nepola JV, et al. Radiographic fracture assessments: which ones can we reliably make? J Orthop Trauma 2000; 14: 379-385. 


\section{ORIGINAL ARTICLE}

11. Field JR, Hearn TC, Caldwell CB. Bone plate fixation: an evaluation of interface contact area and force of the dynamic compression plate (DCP) and the limited contact-dynamic compression plate (LC-DCP) applied to cadaveric bone. J Orthop Trauma 1997; 11: 368-73.

12. Frigg R. Development of the Locking Compression Plate. Injury 2003; 34 Suppl 2: B6-10

13. Borrelli J Jr, Prickett W, Song E, Becker D, Ricci W. Extraosseous blood supply of the tibia and the effects of different plating techniques: a human cadaveric study. J Orthop Trauma 2002, 16 (10): 691-695.

14. Farouk O, Krettek C, Miclau T, Schandelmaier P, Guy P, Tscherne H. Minimally invasive plate osteosynthesis and vascularity: preliminary results of a cadaveric injection study. Injury 1999; 28 Suppl 1: A7-12.

15. Borg T, Larsson S, Lindsjo U. Percutaneous plating of distal tibial fractures. Preliminary results in 21 patients. Injury 2004; 35: 608-614.

16. Jergesen F. Open reduction of fractures and dislocations of the ankle. Am J Surg. 1959; 98: 136151.

17. Ruedi T. Fractures of the lower end of the tibia into the ankle joint: result 9 years after open reduction and internal fixation. Injury 1973; 5: 130-134.

18. Metcalfe BP. Pilon fractures of the tibia. Curr Orthop.2003; 17 (3): 190-199.

19. Mosheiff R, Safran O, Segal D, Liebergall M. The unreamed tibial nail in the treatment of distal metaphyseal fractures. Injury 1999,30: 83-90

20. Blauth M, Bastian L, Krettek C, et al. Surgical options for the treatment of severe tibial pilon fractures: a study of three techniques. J Orthop Trauma. 2001; 15: 153-160.

21. Krackhardt T, Dilger J, Flesch I, Hontzsch D, Eingartner C, Weise K. Fractures of the distal tibia treated with closed reduction and minimally invasive plating. Arch Orthop Trauma Surg.2005; 125(2): 87-94

22. Rhinelander F. The normal microcirculation of diaphyseal cortex and its response to fracture. J Bone Joint Surg 1968; 50A: 784-800.

\section{AUTHORS:}

1. D. Venkateswara Rao

2. K. Venkatasesha Reddy

3. Anvesh Sangepu

\section{PARTICULARS OF CONTRIBUTORS:}

1. Associate Professor, Department of Orthopaedics, SMC/GGH, Vijayawada.

2. Post Graduate, Department of Orthopaedics, SMC/GGH, Vijayawada.

3. Post Graduate, Department of Orthopaedics, SMC/GGH, Vijayawada.
NAME ADDRESS EMAIL ID OF THE CORRESPONDING AUTHOR:

Dr. D. Venkateswara Rao, $4^{\text {th }}$ lane, Subbarao Colony, Flat No-76, H. No. 54/20/2-7A, Opp: Chaitanya College Ladies Hostel, Near Gurudwar Temple, Gurunanak Colony, Vijayawada-520008. E-mail: d_yenkee@yahoo.com

Date of Submission: 08/07/2015. Date of Peer Review: 09/07/2015. Date of Acceptance: 21/07/2015. Date of Publishing: 25/07/2015.

FINANCIAL OR OTHER COMPETING INTERESTS: None 